\title{
Assessing the discharge instructing in the emergency department : Patient perspective
}

\section{Mäkinen, $\mathrm{M}$.}

2019-03

Mäkinen , M , Castren , M , Huttunen , K, Sundell , S , Kaartinen , J , Ben-Meir , M \&

Renholm , M 2019 , ' Assessing the discharge instructing in the emergency department :

Patient perspective ' , International Emergency Nursing , vol. 43 , pp. 40-44 . https://doi.org/10.1016/j.ienj.2018.07.00

http://hdl.handle.net/10138/313104

https://doi.org/10.1016/j.ienj.2018.07.005

draft

Downloaded from Helda, University of Helsinki institutional repository.

This is an electronic reprint of the original article.

This reprint may differ from the original in pagination and typographic detail.

Please cite the original version. 


\title{
Assessing the discharge instructing in the emergency department: Patient perspective
}

\author{
M. Mäkinen ${ }^{\mathrm{a}, *}$, M. Castrén ${ }^{\mathrm{a}}$, K. Huttunen ${ }^{\mathrm{a}}$, S. Sundell ${ }^{\mathrm{a}}$, J. Kaartinen ${ }^{\mathrm{a}}$, M. Ben-Meir ${ }^{\mathrm{b}}$, M. Renholm $^{\mathrm{a}}$

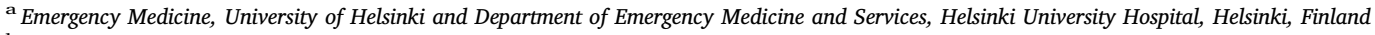 \\ ${ }^{\mathrm{b}}$ Department of Emergency Medicine Cabrini Hospital, Monash University, Australia
}

\section{A R T I C L E I N F O}

\section{Keywords:}

Communication

Discharge

Emergency Department

Instructions

Telephone call

\begin{abstract}
A B S T R A C T
Objective: The objective of the study is to assess how well the emergency department (ED) personnel succeed in instructing the patient at discharge.

Methods: In November and December 2016 at Peijas Hospital ED, Finland, a structured questionnaire was conducted during a phone interview on patients the day after discharge.

Results: A total of 132 patients interviewed. Ninety percent had received discharge instructions from the ED staff, most of them (75\%) about medication. Almost half of the patients (45\%) were satisfied with the communication at discharge, those not satisfied (47\%) felt that the staff did not know enough of their background to give discharge instructions. Of the patients, $20 \%$ thought that they did not have the opportunity to ask questions during the guidance session, and $41 \%$ thought that the session was too short and restricted. Some patients (20\%) felt that the instructions were ambiguous, but 63\% (83/132) felt they were able to follow them well or very well. Conclusion: The pace of care in the ED is fast and duration of the stay is short. The patients must be able to take responsibility of their self-care. Failure to follow medical discharge instructions could lead to non-compliance. Attention should be paid to enhancing the quality of discharge instructing and the instructions provided by the ED personnel, as recurring visits and inquiry calls add to the ED workload.
\end{abstract}

\section{Background}

The increasing number of visits to the emergency department (ED) increases the work of the ED personnel [1]. The reduction of ED readmissions of patients has become a priority. Patient guidance is an important part of readmission reduction interventions. The patient, the provider and environmental factors [2,3] influence the success or failure of information transmission at discharge, increasingly the goal is to discharge patients from the ED as fast as possible with expectations to continue care at home or on the ward. This goal adds significantly to the need of detailed care guidance and instructions [4-6].

Based on the available literature, high-quality ED discharge can be defined as one entity that contains the following main characteristics: informing and educating patients on their diagnosis, prognosis, treatment plan, and expected course of illness, supporting patients in receiving postED discharge care, and coordinating ED care within the context of the health care system [7]. To establish effective patient-centered treatment the patients should be able to discuss their own wishes for self-care, including lifestyles with a practitioner who has the time and who is willing to listen [8]. With good guidance, the patients can take care of themselves better and react more efficiently in the event of a deterioration. In addition, the patient's trust and commitment to their own course of action will improve, as well as their satisfaction with the ED episode of care $[9,10]$. Good discharge communication is also economically cost-effective $[2-5,11,12]$ reducing ED visits, treatment failures and adverse drug events [13].

Call-back programs have been found to be an effective way of improving patient satisfaction and comfort at home while reducing reattendance rates [14-19]. In this study, in order to prevent recurring visits and to follow the quality of discharge guidance, follow-up telephone calls were carried out on patients discharged from the ED within $24-48 \mathrm{~h}$ of attendance.

\section{Aim of the study}

The aim of the study is to assess how well the ED personnel succeed in instructing the patient at discharge by determining how the patient copes with her/his treatment at home. The telephone calls reveal the patients'

* Corresponding author at: Emergency Medicine, University of Helsinki and Department of Emergency Medicine and Services, Helsinki University Hospital, Helsinki, P.O. Box 340, Finland.

E-mail addresses: marja.makinen@hus.fi (M. Mäkinen), maaret.castren@hus.fi (M. Castrén), kirsi.huttunen@hus.fi (K. Huttunen), sami.sundell@wippies.com (S. Sundell), johanna.kaartinen@hus.fi (J. Kaartinen), mbmeir@cabrini.com.au (M. Ben-Meir), marja.renholm@hus.fi (M. Renholm). 


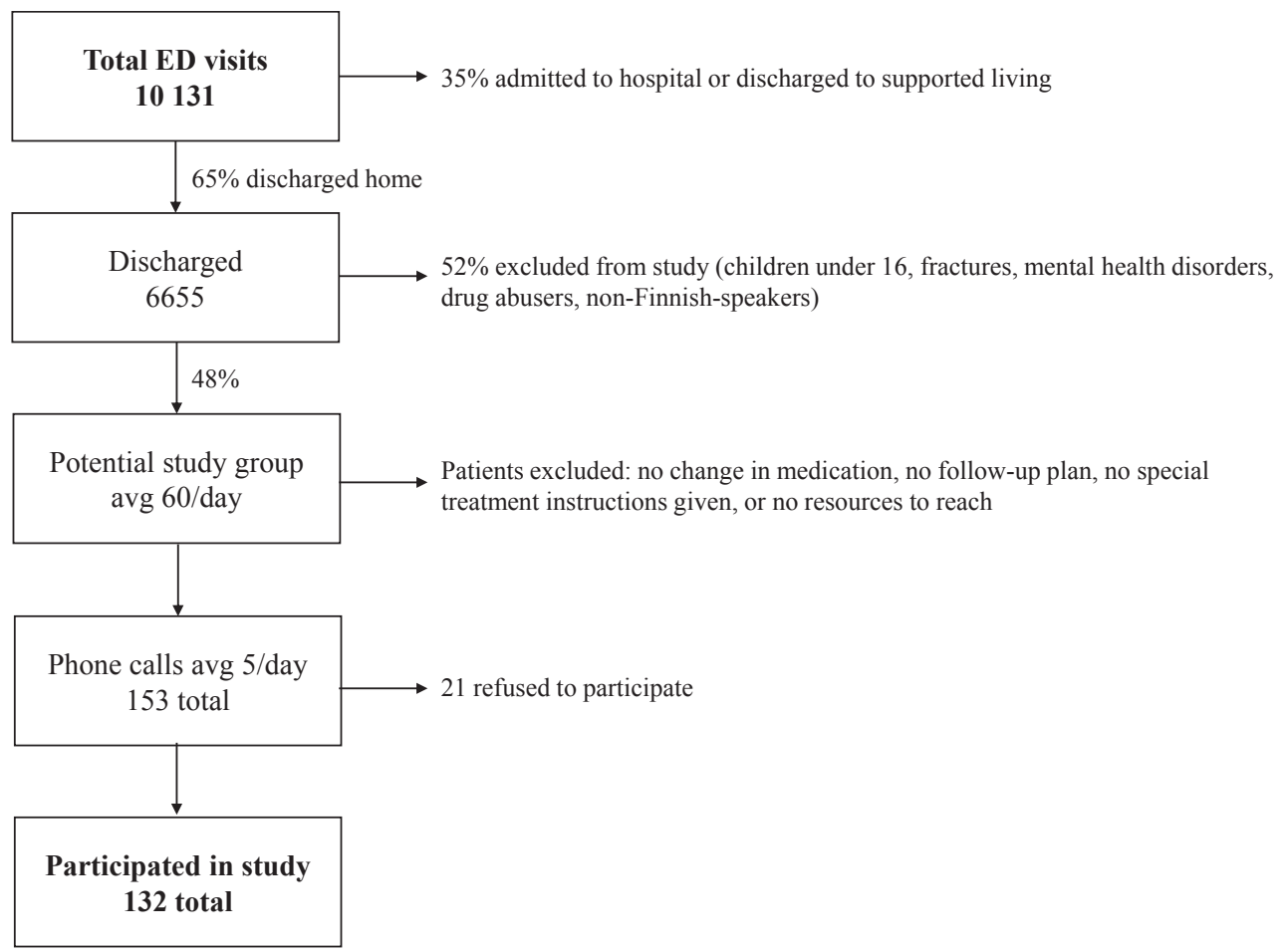

Fig. 1. The patient selection process.

clinical status, their understanding and compliance with the discharge plan, explore their satisfaction with the ED, and provide an opportunity for the patients to give feedback on the quality of care received.

The results can be used to improve the quality of the discharge instructions provided by the ED personnel, so that patients can adjust better in everyday life at home and feel less need for recurring visits or repeat ED or general practitioner contact. Good management of the discharge process supports the patients' self-care, motivation and sense of security. Improving the guidance can help reduce the number of recurrent visits and inquiry calls to the ED. The released resources can be directed to more individual patient care.

\section{Methods and data collection}

The study was conducted in Peijas hospital ED that is part of Helsinki University Hospital. Peijas ED is situated in Vantaa, Finland and has a catchment area of 200,000 inhabitants. The Peijas ED treats 60,000 patients annually. It serves both primary and secondary health care patients and is therefore referred to as combined emergency department.

The study nurse who called the patients was responsible for selecting the patients according to the previously agreed intake and exclusion criteria on the basis of the patient information system (patient records) in home discharge order. The phone calls were made $24-48 \mathrm{~h}$ after the patient had been discharged from the ED in November and December of 2016. During the study period there were 10131 ED visits in total. Out of these visits, $65 \%$ of patients were discharged home without supported living. Young patients ( $0-16$ years old), bone fracture patients, and patients with mental health disorders or drug abuse were excluded, as well as non-Finnish speaking patients. See Fig. 1 for the selection process.

The number of patients a study nurse could select, call and record in one shift was expected to be at least five. One full time nurse was recruited to make these calls. The criteria for calling was that the patient had been discharged from the ED within the last $48 \mathrm{~h}$ at the moment of the call, the patient was able to take the call and answer the questions him/herself, the medication was changed, follow-up care had been planned, and treatment instructions had been given. If the patient was not available at the time of the call, the nurse would call again later. In the telephone interview, the nurse used a predetermined, partially structured questionnaire developed for this study by the researchers. The questions were drawn up on the basis of preliminary literature search and for the purpose of this study [16-18] and initially tested using a selective sample $(n=6)$. The pilot test was used to investigate whether the reserved resources are sufficient and how much time was spent on a single call and whether the interview questions were understandable in the patients' opinion. It was found that the main study was feasible (Fig. 1).

The questions were presented verbally during the calls. The hospital discharge questionnaire was administrated during a telephone interview. The patient was asked about issues related to wellbeing, medication and the ability to follow instructions, as well as satisfaction with discharge instructions and improvement suggestions (Appendix 1). The patients' assessment of their own wellbeing was measured on a scale of $1-10,(1=$ worst possible, $10=$ best possible). Patient satisfaction with the given treatment was measured on a scale of $1-10,(1=$ very dissatisfied, $10=$ very satisfied).

The personnel informed all patients who fulfilled the inclusion criteria in the ED about the ongoing study and that a nurse may call them after their discharge. At this point, the patient had the first opportunity to refuse to participate in the study. At the beginning of the phone call, the nurse asked the patient's consent and informed them about the interests of the study and the data collection. In addition, that the participation in the study was voluntary and the possibility of refusal at any stage was made clear in the beginning of the call. It was also pointed out that refusal to participate would not in any way affect patient treatment or care. The study was a part of a normal development activity.

\subsection{Ethical principles}

All study phases complied with the ethical principles outlined in the Declaration of Helsinki [20]. Research permits were sought from the appropriate research organization. Patients participated in the study voluntarily. The interviewer described the purpose and benefits of the research as well as patient rights during the study. The study participants were adults who were independently able to respond to the 
Table 1

Patients' satisfaction with the discharge instructing.

\begin{tabular}{|c|c|c|c|c|c|c|}
\hline & & $\begin{array}{l}\text { Taking into account the patient's } \\
\text { background } 1\end{array}$ & $\begin{array}{l}\text { Patient's opportunity to ask } \\
\text { questions } 2\end{array}$ & $\begin{array}{l}\text { Timing of the discharge } \\
\text { instructing situation } 3\end{array}$ & $\begin{array}{l}\text { Ability to follow the } \\
\text { instructions } 4\end{array}$ & Patient satisfaction 5 \\
\hline \multirow[t]{4}{*}{1} & Pearson & 1 & & & & \\
\hline & Correlation & & & & & \\
\hline & Sig. (2-tailed) & & & & & \\
\hline & $\mathrm{N}$ & 132 & & & & \\
\hline \multirow[t]{4}{*}{2} & Pearson & ,190* & 1 & & & \\
\hline & Correlation & & & & & \\
\hline & Sig. (2-tailed) & ,028 & & & & \\
\hline & $\mathrm{N}$ & 132 & 132 & & & \\
\hline \multirow[t]{4}{*}{3} & Pearson &, $407^{* *}$ &, $228^{* * k}$ & 1 & & \\
\hline & Correlation & & & & & \\
\hline & Sig. (2-tailed) & ,000 & ,008 & & & \\
\hline & $\mathrm{N}$ & 132 & 132 & 132 & & \\
\hline \multirow[t]{4}{*}{4} & Pearson & ,106 &, 072 &,- 049 & 1 & \\
\hline & Correlation & & & & & \\
\hline & Sig. (2-tailed) & ,226 & ,410 & ,580 & & \\
\hline & $\mathrm{N}$ & 132 & 132 & 132 & 132 & \\
\hline \multirow[t]{4}{*}{5} & Pearson &, 330 &, $214^{*}$ &, $300^{\text {** }}$ &, $227^{* * *}$ & 1 \\
\hline & Correlation & & & & & \\
\hline & Sig. (2-tailed) & ,000 & ,013 & ,000 & ,009 & \\
\hline & $\mathrm{N}$ & 132 & 132 & 132 & 132 & 132 \\
\hline
\end{tabular}

VAR 1 = Taking into account the patient's background.

VAR 2 = Patient's opportunity to ask questions.

VAR 3 = Timing of the discharge instructing situation.

VAR $4=$ Ability to follow the instructions.

VAR 5 = Patient satisfaction.

* Correlation is significant at the 0.05 level (2-tailed).

** Correlation is significant at the 0.01 level (2-tailed).

questions and understand their content. Voluntary compliance with the interview was taken to mean informed consent for the refusal was possible at any stage of the research [20-21]. The objective was to develop patient discharge communication and discharge instructions further. Previous studies have shown the importance of patient education for both patients and society. Therefore this study was part of the development work in daily activities, rather than a pure research project and was considered to be ethically justified.

\subsection{Data analysis}

Descriptive analysis was conducted, and proportions compared using Chi-squared tests. The association between patient satisfaction and the explanatory variables was measured by corresponding 95Confidence intervals (CI 95\%) Cls. All tests were 2-tailed, and $\mathrm{p}<0.05$ was considered as statistical significant. The data was analyzed by means and tested by parametric and non-parametric tests, Student's $t$ test, ANOVA, Pearson Correlation and Regression analysis. Cronbach's alpha was used to test the reliability of the questionnaire. The statistical analyses were carried out by the SPSS 17.0 (SPSS 17.0 SPSS Inc., Chicago, II, USA) for Windows version software package.

\section{Results}

In November and December of 2016, a total of 132/153 (86\%) patients were interviewed for the study. The reliability of the questionnaire was adequate (Cronbach's alpha 0.79). Of the patients, 38\% (50/132) were men and $62 \%(82 / 132)$ were women, $61 \%$ were between 50 and 79 years of age. The minority $(7 \%, 9 / 132)$ were surgical patients. The most common complaints of ED visits were pain $(29 \%, 38 / 132)$ and injuries $(8 \%, 11 / 132)$. The most common diagnoses were wounds, bruises, arrhythmia, dizziness and respiratory tract infections.

According to the interviews, while almost half of the patients $(45 \%$, $59 / 132$ ) were satisfied or very satisfied with the communication in the ED, the other half $(47 \%, 62 / 132)$ felt that the staff had not at all or sufficiently familiarized themselves with the background of the patients to give discharge instructions. Of the patients, 20\% (26/132) thought that they did not have the opportunity to ask questions during the guidance session, and $41 \%(54 / 132)$ thought that the session was too short and restricted. The satisfaction was significantly related to whether the patient's background was taken into consideration (mean 3.03 vs. 3.55 , 95\% CI: 3.07-3.46. P $<0.000$ ), whether the ED staff spent enough time giving the instructions (mean 3.26 vs. 3.83, 95\% CI: 3.33-3.71. $\mathrm{P}<0.000$ ), whether the patient had the opportunity to ask questions (mean 3.63 vs. $4.22,95 \%$ CI: $3.58-4.21 . \mathrm{P}<0.01$ ) and whether the instructions were given so that the patient understood them (mean 3.79 vs. $4.44,95 \%$ CI: 3.84-4.32. P < 0.009) (Table 1 ).

Almost all of the patients $(90 \%, 119 / 132)$ reported that they had received discharge instructions. Most of the patients $(73 \%, 96 / 132)$ received instructions about medication, and written instructions were given to $12 \%(16 / 132)$. Some $(20 \%, 26 / 132)$ of the patients felt that the instructions were somewhat ambiguous, but 63\% (83/132) felt they were able to follow them well or very well. In some cases (4\%, 5/132), additional instructions on medication, pain relief, home treatment and how to relieve the symptoms were required.

More than half of the patients $(57 \%, 75 / 132)$ were very satisfied or satisfied with the instructions they received. Most of the patients $(50.7 \%, 67 / 132)$ received instructions from a physician, and some $(15 \%, 20 / 132)$ received instructions from a nurse, and $28.8 \%(38 / 132)$ from both of them. The examination of background variables showed that the age of the patient had no effect on the understanding of the instructions, nor did the profession of the person giving the instructions. Members of the patient's family seldom $(8 \%, 11 / 132)$ participated in the home care guidance session.

Of the patients, $64 \%(84 / 132)$ were very satisfied or satisfied with the visit to the ED, $70 \%(92 / 132)$ of the patients felt they had received the help they needed. At discharge, $73 \%(97 / 132)$ of the patients felt satisfied (satisfied 39/132 and very satisfied 58/132) The difference was statistically significant $(\mathrm{P}<0.000)$. After the ED visit, 30\% (40/ 132) of patients thought that their condition had improved, and $23 \%$ $(30 / 132)$ of the patients still felt ill (less than 5 on a scale of $1-10)$. Half of them, $51.5 \%$ (68/132), experienced mild to moderate pain, and more 
than ten $(11 \%, 14 / 132)$ had severe pain. More than half of the patients (54\%, 71/132) had visited the ED for the same complaints earlier within 30 days. The reason for that was not analyze in this study.

Of the patients, $79 \%(104 / 132)$ were very satisfied or satisfied that they had received the telephone call. Only 10 patients (8\%) had questions about the discharge instructions related to medical treatment or Xray, and two of the patients wanted the ED physician to contact them.

\section{Discussion}

The ED working model aims to facilitate patient flow, improve the quality and equality of patient care, and deliver a positive patient and family experience. In our study of how well the emergency department (ED) personnel succeed in instructing the patient at discharge, we found that half of the patients were satisfied with discharge communication. The other half of the patients felt that the staff did not know enough of their background to give discharge instruction and hoped for additional guidance. The importance of guidance is increasingly emphasized because the treatment times are short. ED personnel continuously face challenges in the provision of patient-centered care in the time-limited environment, and without complete knowledge of the patients' background and history [1,9]. However, patients expect to receive individual care and discharge guidance.

Emergency nurses require unique knowledge and skills in order to successfully provide emergency care and function within their full scope of practice. The challenge of implementing patient guidance is to arrange additional time and space for personal patient guidance. This may not have been seen as important as it should in a busy working environment.

For many of the patients, the instructions given prior to discharge remained unclear. Similar tendencies have been reported [2,3]. A combination of staff and patient factors may be contributing to the fact that a third of patients were unclear about their discharge instructions. Due to their medical condition, patients may not have been able to learn new information at discharge. It has been shown previously that many patients have poor comprehension of their ED care and discharge instructions, and many of the patients demonstrated a comprehension deficiency in at least one domain of their ED visit. Patients also reported that the instructions provided insufficient information, and that numerous different providers being involved in their care caused confusion $[2,6,7,10]$.

According to the interviewed patients, written instructions were given to the patient quite rarely. Patients hoped for more written material, and those who had received the material had also read it. Previous studies show this practice to be useful because patients are less likely to be readmitted or visit the emergency department again if they have a clear understanding of their discharge instructions [11,12,14-17].

About two-thirds of the interviewed patients had received the treatment which they had been expecting, and half of the patients were satisfied with the ED visit and reported positive feedback. The fact that the other half were not satisfied, highlights the importance of improving patient guidance and instructions. Innovative methods are needed in order to integrate patients into the communication flow, especially in acute care medical settings, in which the patient today often takes a passive role [2,22-24]. Ways must be found to increase the patients' understanding of the medical information and instructions so that they can effectively participate in their own health care. The focus of the discharge instructing should increasingly be extended beyond mere information to include patient understanding, motivation and skills for selfmanagement at home $[8,23]$. It is the role of the medical practitioner responsible for the treatment and discharge to ensure that the instructions regarding the treatment and medication are understood and followed by the patient and their family or close friends. Patients' views and experiences need to be recognized and valued by professionals in order to support their self-care management [8].

It is important that the patients are satisfied with the individual care and instructions they receive in the ED $[24,25]$. ED staff perhaps? have to ensure access to timely, high-quality and evidence-based emergency care with the patient in the center [20].

\section{Limitations}

Limitations of this study include small sample size, a single-institution setting with only one EDs, and a non-randomized design. As a consequence, any findings may not be generalizable to other settings.

\section{Conclusions}

Our results suggest, patient discharge guidance must be improved. Its importance is increasingly emphasized as ED feel pressure to deliver efficiencies and meet time based targets. In order to ensure patient satisfaction, attention should be paid to the discharge communication and instructions. Patients require individual discharge guidance, taking into account their background and their special needs, e.g. pain management while allowing patients the opportunity to ask to make sure that they understand the instructions correctly. All instructions for home care should also be given in written form. Attention should be paid to enhancing the quality of discharge communication and the instructions provided by the ED personnel, so that patients can better take care of themselves at home and hopefully feel less need for recurring visits due to deterioration or inquiry calls because of not knowing what to do.

\section{What shall we learn from this study?}

From this study, it was learned about what distinguishes the professional and the patient's view. The staff should learn to know what issues should be raised in the discharge discussion so that the patients are able to receive individual instructions which are easy to understand, remember and follow at home. In addition, in order to meet the treatment demands of pain patients, it was noted that attention should be paid to this group.

\section{Conflict of interest}

None.

\section{Ethical statement}

This material has not been published in whole or in part elsewhere, the manuscript is not currently being considered for publication in another journal, all authors have been personally and actively involved in substantive work leading to the manuscript, and will hold themselves jointly and individually responsible for its content.

\section{Funding source}

This research did not receive any specific grant from funding agencies in the public, commercial, or not-for-profit sectors.

\section{Appendix A. Supplementary data}

Supplementary data associated with this article can be found, in the online version, at https://doi.org/10.1016/j.ienj.2018.07.005.

\section{References}

[1] Carter EJ, Pouch SM, Larson EL. The relationship between emergency department crowding and patient outcomes: a systematic review. J. Nurs. Scholarsh. 2014;46(2):106-15.

[2] Horstman MJ, Mills WL, Herman LI, Cai C, Shelton Qdaisat T, et al. Patient experience with discharge instructions in postdischarge recovery: a qualitative study. BMJ Open 2017;7:e014842.

[3] Coleman EA, Chugh A, Williams MV, et al. Understanding and execution of discharge instructions. Am. J. Med. Qual. 2013;28:383-91. 
[4] Hamström N, Kankkunen P, Suominen T, Meretoja R. Short hospital stays and new demands for nurse competencies. Int. J. Nurs. Pract. 2012;18:501-8.

[5] Fisher K, Smith K, Gallagher T, Burns L, Morales C, Mazor K. We want to know: eliciting hospitalized patients' perspectives on breakdowns in care. J. Hosp. Med. 2017 Aug;12(8):603-9.

[6] Considine J, Jones D, Pilcher D, Currey J. Patient physiological status at the emergency department-ward interface and emergency calls for clinical deterioration during early hospital admission. J. Adv. Nurs. 2016 Jun;72(6):1287-300.

[7] Improving the Emergency Department Discharge Process. Agency for Healthcare Research and Quality, Rockville, MD. < http://www.ahrq.gov/professionals/ systems/hospital/edenvironmentalscan/index.html/ > (visited 18.6.2018).

[8] Flink M, Ekstedt M. Planning for the discharge, not for patient self-management at home - an observational and interview study of hospital discharge. Int. J. Integr. Care 2017;17(6):1.

[9] Guss DA, Gray S, Castillo EM. The impact of patient telephone call after discharge on likelihood to recommend in an academic emergency department. J. Emerg. Med. 2014 Apr;46(4):560-6.

[10] Samuels-Kalow ME, Stack AM, Porter SC. Effective discharge communication in the emergency department. Ann. Emerg. Med. 2012;60(2):152-9.

[11] Goldsmith $1 \mathrm{H}$, Curtis K, McCloughen A. Incidence, intensity, and impact of pain in recently discharged adult trauma patients: an exploratory study. J. Trauma Nurs. 2017;24(2):102-9.

[12] Caceres JW, Alter SM, Shih RD, Fernandez JD, Williams FK, Paley R, et al. Standardized physician-administered patient-centered discharge protocol improves patients' comprehension. South Med. J. 2017 May;110(5):359-62.

[13] Ellitt GR, et al. Drug related problems after discharge from an Australian teaching hospital. Pharm. World Sci. 2010;32(5):622-30.

[14] Dudas V, Bookwalter T, Kerr KM, Pantilat SZ. The impact of follow-up telephone calls to patients after hospitalization. Dis. Mon. 2002 Apr;48(4):239-48.

[15] Kwok T, Lum CM, Chan HS, Ma HM, Lee D, Woo,. J.A randomized, controlled trial of an intensive community nurse-supported discharge program in preventing hospital readmissions of older patients with chronic lung disease. J. Am. Geriatr. Soc. 2004 Aug;52(8):1240-6.

[16] Guss DA, Leland H, Castillo EM. The impact of post-discharge patient call back on patient satisfaction in two academic emergency departments. J. Emerg. Med. 2013 Jan;44(1):236-41.

[17] Harrison JD, Auerbach AD, Quinn K, Kynoch E, Mourad M. Assessing the impact of nurse post-discharge telephone calls on 30-day hospital readmission rates. J. Gen. Intern. Med. 2014 Nov;29(11):1519-25.

[18] Record JD, Niranjan-Azadi A, Christmas C, Hanyok LA, Rand CS, Hellmann DB, et al. Telephone calls to patients after discharge from the hospital: an important part of transitions of care. Med. Educt. Online 2015 Apr;29(20):26701.

[19] Interview script for telephone follow-up of discharged patients from Cabrini ED. ED management committee, briefing paper Department of Emergency Medicine, Cabrini Hospital, Melbourne Australia.

[20] WMA Declaration of Helsinki - Ethical Principles for Medical Research https:// www.wma.net/.../wma-declaration-of-helsinki-ethical-principles (visited 18.6. 2018).

[21] 1326/2010 English - www.finlex.fi > ... > Translations of Finnish acts and decrees ) 2010... - Finlex Terveydenhuoltolaki 1326/2010 (Finlex) (visited 23.10.2017).

[22] Vashi A, Rhodes KV. Sign right, here and you're good to go": a content analysis of audiotaped emergency department discharge instructions. Ann. Emerg. Med. 2011 Apr;57(4):315-22.

[23] Gignon M, Ammirati C, Mercier R, Detave M. Compliance with emergency department discharge instructions. J. Emerg. Nurs. 2014 Jan;40(1):51-5.

[24] Horstman MJ, Stewart DE, Naik AD. Improving patients' postdischarge communication: making every word count. Circulation 2014;130:1091-4.

[25] Sheikh H, Brezar A, Dzwonek A, Yau L, Calder LA. Patient understanding of discharge instructions in the emergency department: do different patients need different approaches? Int. J. Emerg. Med. 2018 Feb 8;11(1):5. 